\title{
Growth Rate Characteristics during Early Marine Life and Sea-entry Conditions of Juvenile Chum Salmon Originating from Two Rivers along the Pacific Coast of Hokkaido, Japan
}

\author{
Kentaro Honda $^{1}$, Tatsuya Kawakami ${ }^{2}$, Kotaro Shirai ${ }^{3}$, Takashi Kitagawa ${ }^{3}$, and Toshihiko Saito ${ }^{1}$ \\ ${ }^{1}$ Hokkaido National Fisheries Research Institute, Japan Fisheries Research and Education Agency, 2-2 \\ Nakanoshima, Toyohira-ku, Sapporo, Hokkaido 062-0922, Japan \\ ${ }^{2}$ Atmosphere and Ocean Research Institute, The University of Tokyo, 2-106-1 Akahama, Otsuchi-cho, Iwate 028- \\ 1102, Japan \\ ${ }^{3}$ Atmosphere and Ocean Research Institute, The University of Tokyo, 5-1-5 Kashiwanoha, Kashiwa, Chiba 277- \\ 8564, Japan
}

Keywords: early marine life, growth rate, otolith daily growth increments, sea-entry condition

Juvenile chum salmon originating from rivers along the Pacific coast of Hokkaido, Japan migrate northwards to the Sea of Okhotsk, typically passing off the easternmost part of Hokkaido (Irie 1990; Chistyakova and Bugaev 2013). Japanese juvenile chum salmon are likely to undergo growth-dependent mortality (Honda et al. 2017, 2018). Thus, understanding a suitable release timing and body size to make fish grow faster after sea entry is desired, to improve release strategies from Japanese hatcheries.

In this study, juvenile chum salmon originating from the Tokachi $\left(42^{\circ} 41^{\prime} \mathrm{N}, 143^{\circ} 40^{\prime} \mathrm{E}\right)$ and Yurappu $\left(42^{\circ} 16^{\prime} \mathrm{N}, 140^{\circ} 17^{\prime} \mathrm{E}\right)$ rivers consisting of three sampling-year groups each [2005 ( $\left.n=23,72.0-90.0 \mathrm{~mm} \mathrm{FL}\right), 2007$ $(n=34,72.0-107.1 \mathrm{~mm} \mathrm{FL})$, and $2009(n=34,64.0-94.0 \mathrm{~mm}$ FL) for Tokachi and $2013(n=27,93.5-113.9 \mathrm{~mm}$ FL), 2014 ( $n=31,92.2-115.9 \mathrm{~mm}$ FL), and $2016(n=25,91.9-104.6 \mathrm{~mm}$ FL) for Yurappu] sampled in June-July at Konbumori (42 $50-56^{\prime} \mathrm{N}, 144^{\circ} 34^{\prime} \mathrm{E}$; $~ 80 \mathrm{~km}$ northeast of the Tokachi river mouth) and at Atsuga or Harutachi $\left(42^{\circ} 15-24^{\prime} \mathrm{N}, 142^{\circ} 12-29^{\prime} \mathrm{E} ; \sim 150-180 \mathrm{~km}\right.$ east of the Yurappu river mouth), respectively, were used. We examined the relationship for each group between back-calculated growth rate (mean daily growth in FL) during early marine life of juvenile chum salmon and their estimated dates and FLs at sea entry, using daily-increment analysis of otoliths (see Honda et al. 2017 for methodology).

Average $( \pm \mathrm{SD})$ growth rates of Tokachi specimens were $0.57 \pm 0.11 \mathrm{~mm} /$ day, $0.61 \pm 0.11 \mathrm{~mm} /$ day, and 0.55 $\pm 0.08 \mathrm{~mm} /$ day for groups sampled in 2005, 2007, and 2009, respectively, whereas those of Yurappu specimens were $1.06 \pm 0.11 \mathrm{~mm} /$ day, $0.99 \pm 0.11 \mathrm{~mm} /$ day, and $0.88 \pm 0.08 \mathrm{~mm} /$ day for groups sampled in 2013,2014 , and 2016. Any remarkable trends were not found in the relationships between growth rates and dates and FLs at sea entry for each sampling-year group except for the 2005-Tokachi group of which fish that migrated to the sea later showed relatively higher growth rate. Growth rates of Yurappu specimens were even higher than those originating from the same river sampled at Konbumori ( $\sim 400 \mathrm{~km}$ east of the Yurappu river mouth) during 2005-2014 (0.71 \pm $0.12 \mathrm{~mm} /$ day, $n=27$ ) estimated by Honda et al. (2017). The few remarkable relationships between growth rate and date and FL at sea entry were possibly a resulte of our small sample size and/or from the fact that we only sampled fish selected through growth-dependent survival mechanisms during earlier marine life. Moreover, higher growth rates observed by Yurappu specimens particularly those sampled in 2013 and 2014, which are being assumed as poor-return stocks (Watanabe et al. 2018), may suggest that only fish with such high growth rates could survive even in years when massive mortality took place.

Acknowledgments - This study was partially supported by the Cooperative Program (No. 140, 2017) of Atmosphere and Ocean Research Institute, The University of Tokyo.

\section{REFERENCES}

Chistyakova, A.I. and Bugaev, A.V. 2013. A portion of hatchery pink and chum salmon juveniles during migration period in the Okhotsk Sea in 2012. Bull. Pac. salmon studies Russ. Far. East 8: 150-171. (In Russian)

Honda, K., Kawakami, T., Suzuki, K., Watanabe, K., and Saito, T. 2017. Growth-rate characteristics of juvenile chum salmon Oncorhynchus keta originating from the Pacific coast of Japan and reaching Konbumori, eastern Hokkaido. Fish. Sci. 83: 987-996. 
Honda, K., Kawakami, T., Saito, T., and Urawa, S. 2018. First report of growth rate of juvenile chum salmon Oncorhynchus keta captured in the Sea of Okhotsk offshore. Ichthyol. Res. doi: 10.1007/s10228-018-0643-6

Irie, T. 1990. Ecological studies on the migration of juvenile chum salmon Oncorhynchus keta during early ocean life. Bull. Seikai Natl. Fish. Res. Inst. 68: 1-142. (In Japanese with English abstract)

Watanabe, K., Honda, K., and Saito, T. 2018. Chum salmon Oncorhynchus keta Japanese stocks, The current status of international fishery stocks (FY 2017). Fisheries Agency of Japan and Japan Fisheries Research and Education Agency, Tokyo. No. 60. (In Japanese, available at http://kokushi.fra.go.jp/index-2.html) 